\title{
LA ESTÉTICA MUSICAL EN GALENO DE PÉRGAMO*
}

\author{
Inmaculada Rodríguez-Moreno \\ Universidad de Cádiz \\ inma.rodriguez@uca.es
}

\section{RESUMEN}

El artículo analiza la posición de la música en el pensamiento de Galeno, quien la coloca dentro de las artes liberales en calidad de teoría de la armonía. El pergameno, de acuerdo con sus antecesores, es consciente de su papel en la medicina por su capacidad para influir en el èthos. Además, aboga por la función paidéutica y ética de la disciplina musical, de modo que esta se convierte en un complemento fundamental en la formación de todo médico, habida cuenta de sus aplicaciones prácticas.

Palabras Clave: Galeno, música, educación, èthos, medicina, ciencia, artes liberales, artes serviles.

MUSICAL AESTHETICS IN GALEN OF PERGAMUM

\section{ABSTRACT}

This paper analyzes the position of music in the thought of Galen, who places it inside the liberal arts as theory of harmony. The Pergamenus, according to his predecessors, is aware of its role in medicine because of its ability to influence in the éthos. In addition, he defends the paideutical and ethical function of the musical discipline, so that it becomes a fundamental complement in the training of every doctor, due to its practical applications.

KEYWORDS: Galen, music, education, èthos, medicine, science, liberal arts, servil arts.

Desde la perspectiva corporal, la enfermedad es producto de una alteración de los elementos o humores, de un exceso o falta de alimentos, de un esfuerzo o una trasgresión de los límites de lo caliente o lo frío, de lo seco o lo húmedoํㅡㄹ es decir, de los denominados homeómeros ${ }^{2}$. Ciertamente, el reto de la medicina estriba en mantener cierta simetría entre estos aspectos, la armonía total opuesta a la enfer-

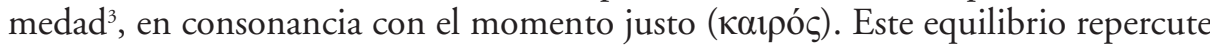
a nivel anímico ${ }^{4}$ y para lograrlo, se recurre a diversos métodos curativos encaminados a la conservación de la salud y la prevención o alivio de la enfermedad. Pueden ser farmacológicos, naturales o extrañamente mágicos, aunque estos últimos se ajustan a una concepción divina o demónica de la enfermedad ${ }^{5}$, promovida, en palabras de Hipócrates, por «magos, purificadores, charlatanes y embaucadores» ${ }^{6}$. Entre estos 
procedimientos se incorpora la música como herramienta terapéutica, debido a su capacidad para restablecer la armonía en el alma como un «fármaco», siempre en función del tiempo empleado y de la predisposición del individuo hacia la melodía ${ }^{7}$.

Según esta idea, los pitagóricos fueron los pioneros en practicar la melote-

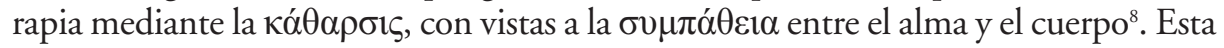
farmacopea musical buscaba purificar el espíritu a través de cantos y melodías ejecutados con simplicidad y con acompañamiento de la lira o la voz, para conseguir sueños sosegados, agradables o proféticos ${ }^{9}$. Asimismo, Pitágoras concedía una gran importancia a las غ̇ं $\omega \delta \alpha i ́$ como fusión de música y palabra, ya que creía en su capacidad curativa, confiriéndoles una mayor efectividad que a los fármacos ${ }^{10}$.

En este sentido, existen ciertos ritmos y melodías - diatónicas, cromáticas y armónicas - capaces no solo de controlar y curar enfermedades, sino también de refrenar las pasiones del alma: dolor, ira, piedad, celos, temores, deseos, apetitos, orgullo, negligencia y vehemencia ${ }^{11}$. En todas ellas, la música ejerce una acción catárquica en el espíritu a través de sus modos, pues cada uno de ellos posee propiedades, que infieren tanto a nivel somático como psíquico.

* El estudio se inscribe en el Proyecto de Investigacion I+D+i Obras de Galeno: medicinaotras ciencias-literatura-pensamiento (FFI2017-82850-R), financiado por el Ministerio de Economia y Competitividad y dirigido por Luis Miguel Pino Campos, Catedratico de Filologia Griega de la Universidad de La Laguna.

${ }^{1}$ Cf. Souilhé, 1919: 34.

${ }^{2}$ Los que tienen partes similares entre ellos. Cf. Arist., Met., 984 a 14; 988 a 28. Grimaudo, 2008: 13-17.

${ }^{3}$ Gal., De sanitate tuenda, 6. $13 \mathrm{~K}$.

${ }^{4}$ Arist., de An., 1. 4. 407 b; Macr., Somn., 1. 44. Cf. Moutsopoulos, 1959: $42-44$.

${ }^{5}$ Cf. Zaragoza, 1992: 365-369.

${ }^{6} \mathrm{Hp} .$, Morb. sacr., 1. 22-25 L. Dentro del ámbito de la magia y la superstición, la palabra tiene poder para apartar los malos démones que causan la enfermedad. Cf. Vázquez, 1994: 345-346; Rodríguez, 1996: 349-355; 2002: 79-90.

${ }^{7}$ Aristid. Quint., 2. 4. 1-12.

${ }^{8}$ Porph., VP., 33-34; Iamb., VP., 25. 114.

${ }^{9}$ Iamb., VP., 15. 65; 25. 110-111.

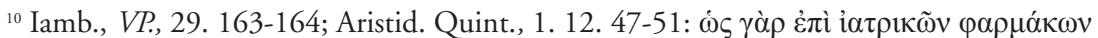

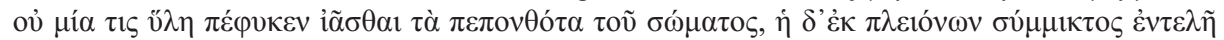

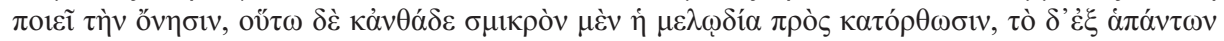
$\tau \tilde{\omega} \nu \mu \varepsilon \rho \tilde{\omega} \nu \sigma v \mu \pi \lambda \eta \rho \omega \theta \dot{\varepsilon} v \alpha \nu ่ \tau \alpha \rho \kappa \varepsilon ́ \sigma \tau \alpha \tau o v$. Pues como en los fármacos medicinales una materia cualquiera aislada no puede curar las dolencias del cuerpo, mientras que la que está formada de la mezcla de más consigue un beneficio completo, así también en esto la melodía hace poco para la curación, pero el conjunto compuesto por la combinación de todas las partes es del todo suficiente.

${ }^{11}$ Iamb., VP., 15. 64; 25. 114. Los instrumentos también intervienen en la meloterapia, de modo que se aconsejan los sones de la lira en tanto que se desechan los de la flauta por contaminar el espíritu, Aristid. Quint., 2. 18; Iamb., VP., 25. 111. Aristóteles censura la flauta por no aportar carácter moral y por su poder orgiástico: Pol., 1341 a 21-22. Cf. Otaola, 2011: 91-108. 
La música, a pesar de estos indicios de su rol dentro del ámbito pitagórico ${ }^{12}$, en principio no formaba parte de un programa pedagógico ${ }^{13}$. Sin embargo, a medida que se va adquiriendo una mayor conciencia de sus impactos éticos en virtud de determinadas armonías y ritmos, se fue abriendo paso de manera progresiva dentro de la $\pi \alpha 1 \delta \varepsilon i ́ \alpha$ reglada de los jóvenes.

Esta disciplina, por su carga didáctica y moral, junto a otros valores, se convierte en una materia relevante en el plano educativo, según se aspira a demostrar en el presente estudio con la figura de Galeno, cuyo pensamiento se centra en las teorías platónicas y aristotélicas. El pergameno, pues, respalda su inclusión en la formación integral de todo médico, al tiempo que se plantea la cuestión de cuál es su estatus entre las ciencias. Por esta razón, antes de abordar el análisis de sus testimonios a este respecto, es conveniente realizar un escueto recorrido por la estética musical precedente, con la finalidad de entender su enfoque.

\section{CONSIDERACIONES \\ SOBRE EL PODER EDUCATIVO Y ÉTICO DE LA MÚSICA}

Sin duda el $\tilde{\eta} \theta$ o obstante, ambos vocablos encierran un significado distinto. El primero comporta una idea de tensión y se refiere a una combinación de los intervalos que componen una escala, la cual representa la $\alpha \rho \mu o v i ́ \alpha$ propiamente dicha ${ }^{14}$. El segundo se refiere a una sucesión de sonidos o una fórmula melódica, cuyas relaciones interválicas específicas definen su nombre (doria, por ejemplo), pero también en exclusiva un $\tilde{\eta} \theta 0 \varsigma^{15}$. Así, las armonías conforman ciertos estilos característicos de determinadas regiones o pueblos. Las auténticamente griegas son tres: la dórica, la eólica y la jónica, a las que se unen otras de origen extranjero, como la frigia y la lidia o la mixolidia ${ }^{16}$, con unas connotaciones menos positivas ${ }^{17}$. Todas se atienen a una serie de peculiaridades que van a inferir en el cuerpo tanto a nivel físico como psíquico. Desde el punto de vista anímico, la armonía doria casa con los acentos viriles ${ }^{18}$; la frigia muestra un carácter entusiástico ${ }^{19}$; la jonia, uno austero y duro, a la vez que blando y afeminado ${ }^{20}$, y, por último, la lidia, uno trenódico, afín a los lamentos ${ }^{21}$.

\footnotetext{
${ }^{12}$ Para la música dentro de la poesía épica y la lírica, cf. Rodríguez, 2018.

${ }^{13}$ Para el carácter educador de la música, cf. Ps.-Plu., 1146 A-F. Fubini ,1988: 45-48.

${ }^{14}$ Cf. Landels, 1999: 86-109; Hagel, 2010: 26-29.

${ }^{15}$ Tatarkiewicz, 1991: 232-235.

${ }^{16}$ Cf. Winnington, 1968: 21-47; Hagel, 2010: 1-52.

${ }^{17}$ Arist., Pol., 1342 a 28-1342 b 19.

${ }^{18}$ Arist., Pol., 1342 b.

${ }^{19}$ Arist., Pol., 1340 a; 1342 b; Lucianus, Herm., 1.

${ }^{20}$ Ath., 14. 625 b; Pl., R., 398 e.

${ }^{21}$ Schol. Pi. O. 5. 44; Schol. Pi. N., 8. 24; Pl., R., 398 e; Arist., Pol., 1342 b.
} 
Para Aristóteles, cada $\dot{\alpha} \rho \mu o v i ́ \alpha$ provoca un efecto particular en los oyentes ${ }^{22}$ : la mixolidia infunde melancolía y ensimismamiento; la doria, compostura y moderación, y la frigia, entusiasmo. Igualmente, los ritmos también tienen sus singularidades anímicas, en cuanto que unos despiertan serenidad, y otros, movimientos, dado que el alma es o tiene armonía ${ }^{23}$. Por tanto, todos estos aspectos demuestran el papel ético de la música debido a su cualidad para interpretar el ritmo del alma, de forma que esta es capaz de experimentar las mismas sensaciones transmitidas por la música, las cuales, a su vez, se reflejan en el cuerpo ${ }^{24}$.

A causa de este valor ético, resulta esencial la introducción de la disciplina músical en la $\pi \alpha 1 \delta \varepsilon \varepsilon^{25} \alpha^{25}$, puesto que en ella participan tres elementos básicos, según Platón $^{26}$, las palabras, la armonía y el ritmo, o cuatro, a juzgar por el pasaje de Arístides Quintiliano ${ }^{27}$ :

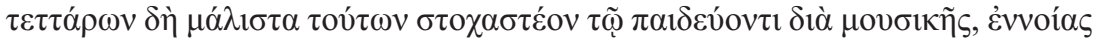

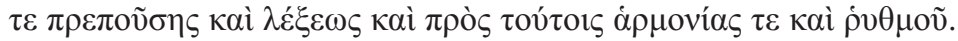

Quien educa por medio de la música debe poner su atención a estos cuatro elementos, el concepto que conviene y la dicción, y, junto a estos, la armonía y el ritmo.

La música no solo es un mecanismo válido para obtener un estado saludable a niveles físico y psíquico, sino que además influye en el comportamiento del individuo en calidad de ser político ${ }^{28}$. En este sentido, igual puede inculcar pasiones innobles, como enmendar una conducta incorrecta o moldear el carácter en sentido positivo o negativo, de acuerdo con la predisposición de este hacia la justicia ${ }^{29}$. Aristóteles, por su lado, ratifica su poder mimético, capaz de despertar pasiones y ciertos estados anímicos, con arreglo al tipo de melodía ${ }^{30}$.

Su instrucción, pues, ocupa un puesto de honor en la educación juvenil a causa de su función ético-pedagógica. La defensa de esta importancia es asumida por Platón a raíz de su concepto didáctico-musical, siguiendo la estela trazada anteriormente

${ }^{22}$ Pol., 1340 a 14-b 19.

${ }^{23}$ Cf. Pl., Lg., 789 a-791 b; Ti., 88 c-89 d; Ath., 14.628 c.

${ }^{24}$ Arist., Pol., 1341 b-1342 b. Rodríguez, 2009: 237-255; Suñol, 2018: 139-155, especialmente 148-151. Son varios los ejemplos de la música utilizada como medicina para el cuerpo, en función del grado de sensibilidad del individuo hacia la melodía y el ritmo. Theoc., 11. 1-6; S. E., M., 6. 8; 6. 10; 6. 17; 6. 32; Hom., Il., 9. 186-189; Phld., Mus., 9. 71; Iamb., VP., 25. 112; Plu., 1146 F. Marino describe cómo el mismo Proclo pone en práctica sobre su persona la antigua meloterapia pitagórica. Marin., Procl., 19-20 (489-514) [Saffrey-Segonds].

${ }^{25}$ Pl., Lg., 659 e; Ti. Locr., 104 b.

${ }^{26}$ Pl., R., 398 d. Cf. Grg., 502 c; R., 395 b-d; 392 a-d.

${ }^{27} 2.7 .13-15$.

${ }^{28}$ Pl., R., 425 a-425 e; 401 e; 411 d-e; Lg., 653 c-654 a; 656 d-e; Ti., 88c. Cf. Aristid. Quint., 2. 3. 10-27. Platón especifica cuáles son las características de cada uno de los modos y ritmos musicales. R., 398 a-e; 399 a-e; Lg., 654 a-e; 812.

${ }^{29} \mathrm{Pl} ., R_{\text {. }}, 400$ a; 401 e.

${ }^{30}$ Pol., 1340 a-b. Cf. Pl., Lg., 665 a-e; 668 a-670 e; 812 c. Cf. Pajares, 2014: 35-38. 
por los pitagóricos. Entre estos, el gran adalid del carácter moralista y pedagógico de la música fue Damón de Atenas, de quien no se conserva escrito alguno, aunque se conoce su ideario de forma indirecta a través a Platón, Aristóteles, Filodemo, Arístides Quintiliano o Plutarco, además de otros tratadistas ${ }^{31}$. Los cimientos de su postura se sustentan en el estrecho vínculo entre los sonidos y la ética y en la superioridad de la música frente a la gimnasia. Incluso, para aquel, este arte constituye una vía para acceder a todas las virtudes, por lo que su aprendizaje resulta básico al infundir valor, sabiduría y sentido de la justicia ${ }^{32}$. Por el contrario, para Aristóteles, si la cultura física es esencial a la hora de desarrollar la hombría, la música plantea una dificultad por su pertenencia al ámbito del ocio ${ }^{33}$, y consecuentemente instiga tanto a la virtud como al vicio ${ }^{34}$. Por este motivo, recomienda hacer un uso noble de ella, pues solo

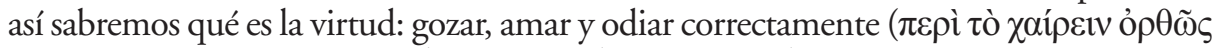

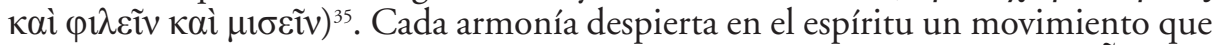
imita a aquella, tanto en sentido positivo como negativo, un modo de ser $(\tilde{\hat{\eta}} \theta 0 \varsigma)^{36}$ :

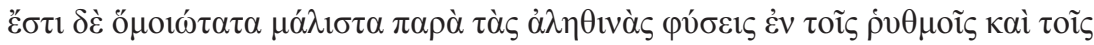

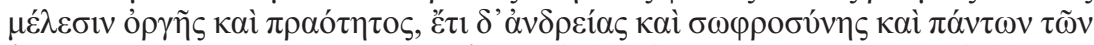

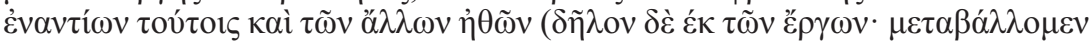

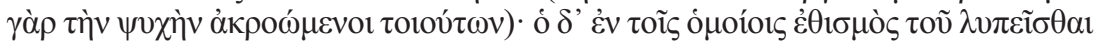

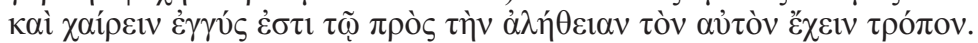

En los ritmos y las melodías existen muchas imitaciones de las verdaderas naturalezas de la ira y de la mansedumbre, e incluso de la hombría y de la templanza y de todos sus contrarios y demás formas de ser (es evidente por los hechos: pues cambiamos el ánimo al escuchar tales sonidos); y la costumbre de sentir aflicción y de gozar en semejantes situaciones está próxima a la misma manera de sentir conforme a la verdad ${ }^{37}$.

El alma es movimiento, al igual que el sonido, de suerte que entre ambos se establece una correspondencia directa y recíproca, como defienden Damón y Aristóteles. Esta concepción queda ejemplificada en la anécdota del joven que, ebrio y excitado por los sones de la flauta, fue ante la puerta de su amada, una mujer de rectas costumbres, con la intención de prenderle fuego. Tras la intervención de Pitágoras o Damón, el flautista cambió la melodía frigia que estaba interpretando al modo dorio, mucho más solemne y lento, y de inmediato el enamorado depuso su actitud ${ }^{38}$.

${ }^{31}$ Cf. 1. 381-384 DK; Comotti, 1986: 28-29; Moutsopoulos, 1959: 185-194.

${ }_{32}$ Phld., Mus., frag. 100 Delattre.

${ }_{33}$ Pol., 1337 b 25-1338 b.

${ }^{34}$ Pol., 1339 a-1339 b.

${ }^{35}$ Pol., 1340 a-b.

${ }^{36}$ Pol., 1340 a $19-24$.

${ }^{37}$ Cf. Pl., R., 395 a-397 c.

${ }^{38}$ Según las fuentes, la anécdota se atribuye a Pitágoras o Damón, como también dicen que la primera melodía está compuesta en el modo dorio y la segunda en el frigio. Damon, frag. A. 8 DK; Posidon., frag. 168 Edelstein-Kidd; Iamb., VP., 25. 112; S. E., M., 6. 8; Quint., Inst., 1. 10. 32; Plu., 1146 F. Independientemente de la armonía, los modos se ajustaban a ciertos caracteres o estados anímicos bien de manera positiva bien negativa. 
Junto a las armonías, hay ritmos que contribuyen a un estilo de vida ordenado y valeroso. Para ello, es necesario conocer cuáles son los adecuados y cómo estos se adaptan, en función del pie métrico y la melodía, al carácter de un hombre con tal predisposición. En este sentido, como refiere Platón ${ }^{39}$, uno de los puntos fuertes de la doctrina de Damón reside en el hecho de que la música es esencial en la $\pi \alpha 1 \delta \varepsilon i ́ \alpha$, puesto que su uso correcto certifica la corrección de los vicios, la educación del espíritu y la enseñanza de la virtud. Con todo, el arte musical, como instrumento pedagógico, orienta al alma a la hora de captar la belleza, tanto en las obras de arte como en las naturales ${ }^{40}$. En consecuencia, hay que saber distinguir cuál es la música correcta y desechar la opuesta a las leyes del Estado ${ }^{41}$, cuya responsabilidad es reglamentar la educación en material musical ${ }^{42}$.

Por su parte, Platón define como música correcta la propia de la Razón, es decir, la no audible, opuesta a la audible, la cual está ligada al placer. Mientras que esta es rechazada por el filósofo por su tendencia hedonista y su vinculación a los sentidos y al mundo material, la primera, a causa de su pertenencia a la esfera de la бoфía, se desliga de los sentidos, de manera que se convierte en un perfecto filosofar ${ }^{43}$, al tiempo que se aproxima a la noción de Belleza y Verdad por contener la esencia del $\Lambda$ ó $\varsigma^{44}$. Interpreta la música como ciencia y arte $(\tau \dot{\varepsilon} \chi \nu \eta)$, y como tal su fin es la composición de cantos ${ }^{45}$ conectados a la esfera de la $\eta \dot{\delta} \delta \eta^{4} \eta^{46}$ y agradar a los mejores hombres como un mecanismo de virtud y educación ${ }^{47}$. A su vez, en calidad de ciencia, es filosofía en cuanto que constituye la suprema sabiduría $\left(\sigma o \varphi^{\prime} \alpha\right)^{48}$ :

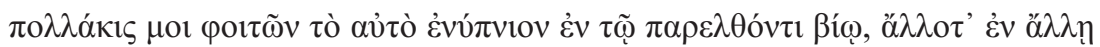

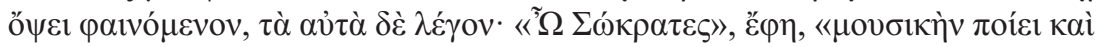

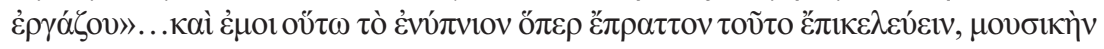

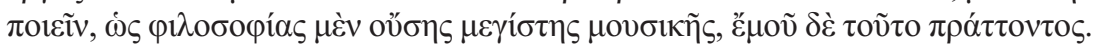
En muchas ocasiones, a lo largo de mi vida, se me había aparecido con frecuencia en sueños la misma visión, que, por un lado, se mostraba cada vez con distinta apariencia, y, por otro, me decía lo mismo: «Sócrates, crea música y trabaja» ... Así la visión me ordenaba eso que yo hacía, crear música, porque la música más excelsa es la filosofía, y yo me dedicaba a eso.

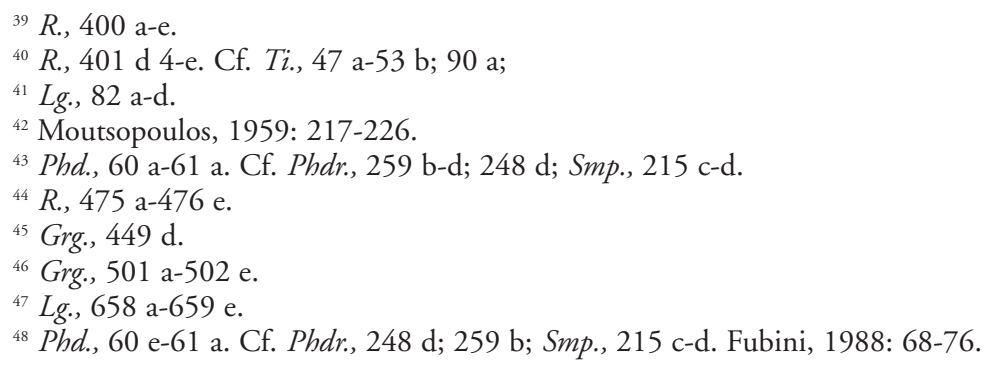


También Aristóteles cree en el poder paidéutico de la música, puesto que ella infunde virtud ${ }^{49}$. No obstante, a diferencia de la postura damoniana y platónica, no critica su pertenencia al ámbito del ocio ${ }^{50}$, sino que la cataloga como una disciplina "noble y liberal» ${ }^{51}$ y una preparación para valorar lo bello y recto, amén de otros actos sublimes ${ }^{52}$ :

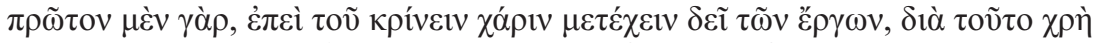

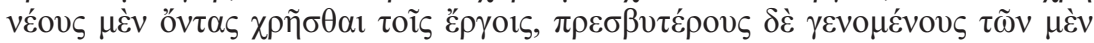

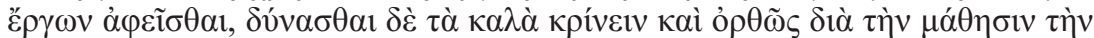

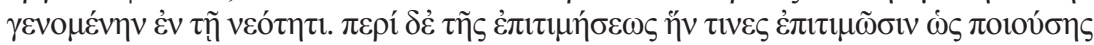

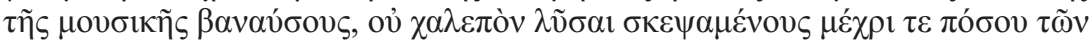

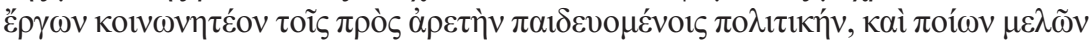

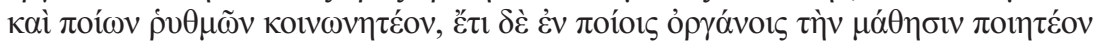

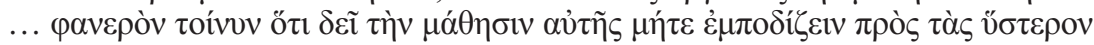

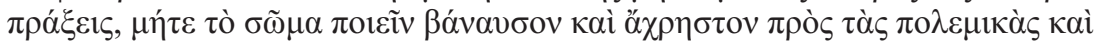

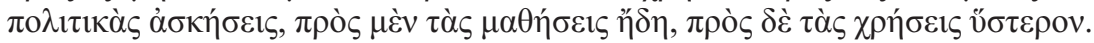
En primer lugar, puesto que es necesario participar de las ejecuciones para juzgar, los jóvenes, por esto, deben hacer uso de las ejecuciones y, cuando sean mayores, abstenerse de ellas, y poder juzgar las cosas bellas y gozar rectamente gracias al conocimiento adquirido en la juventud. Acerca del reproche que algunos lanzan de que la música los hace vulgares, no es difícil refutarlo si ellos examinan hasta qué punto deben participar de las ejecuciones los que se educan en la virtud política, y de qué melodías y ritmos, e incluso en qué instrumentos deben hacer el aprendizaje ... Por consiguiente, es evidente que el aprendizaje de ella (la música) no debe ser un obstáculo para las actividades futuras, ni hacer al cuerpo vulgar e inútil para las prácticas militares y políticas, tanto en las enseñanzas actuales, como en las prácticas posteriores.

El estagirita apoya el talante hedonista de la música, ya que los sentidos se

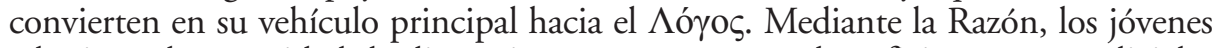
adquieren la capacidad de discernir qué armonías son beneficiosas o perjudiciales para su ascenso a la virtud ${ }^{53}$. Por tanto, el filósofo no pone restricciones a las armonías de este arte, sino que considera fundamental su conocimiento, de modo que con ellas el artista puede escoger la verdad a imitar. Además, explica que la música influye en el ánimo mediante la catarsis ${ }^{54}\left(\kappa \alpha \dot{\theta} \theta \alpha \rho \iota_{\varsigma}\right)$, concepto para el que no encuentra una definición ${ }^{55}$, aunque sí expone sus efectos ${ }^{56}$ :

${ }^{49}$ Cf. Suñol, 2009: 202-206; 2012: 138-154; 2017: 7-35.

${ }^{50}$ Pol., 1337 b; 1338 a; 1340 b; 1341 a.

${ }^{51}$ La música se integra dentro de las artes liberales, al ser entendida como teoría de la armonía, no mera interpretación práctica. Cf. Tatarkiewicz, 1987: 39-43; 79-86.

${ }^{52}$ Pol., 1340 b 35-1341 a 9. Cf. Freitas, 2018: 465-371.

${ }^{53}$ Pol., 1340-1341.

${ }^{54}$ Pol., 1341 b; 1342 a-b.

${ }^{55}$ El filósofo declara su intención de explicar con mayor detenimiento este concepto más adelante en la Poética, quizás en el libro II, en la actualidad perdido.

${ }^{56}$ Pol., 1342 a 9-15. Cf. Suñol, 2017: 7-35. 


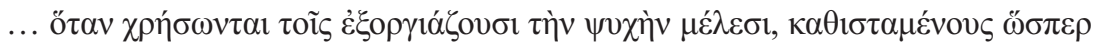

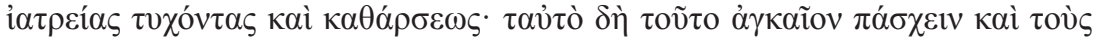

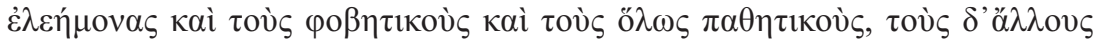

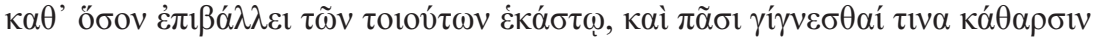

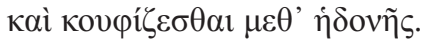

... Cuando se usan las melodías que embelesan frenéticamente el alma, vemos que están poseídos como si encontraran curación y purificación. Esto mismo deben experimentar los compasivos, los temerosos y, en general, los poseídos por una pasión, y los demás según cuanto de tales sentimientos toque a cada uno, y todos tendrán cierta purificación y se sentirán alivio además de placer.

Así, tal arte se convierte en una medicina para el alma al imitar pasiones o sentimientos de los que nos podemos liberar o purificar ${ }^{57}$ :

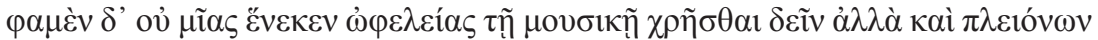

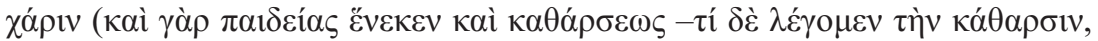

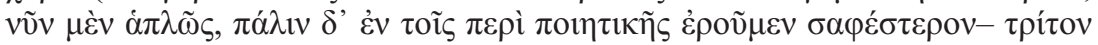

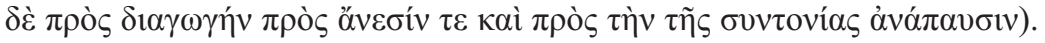

$\mathrm{Y}$ afirmamos que es preciso servirse de la música no por un único beneficio, sino por muchos (pues por la educación y la purificación -y qué decimos de la purificación, ahora simplemente la mencionamos, pero de nuevo la explicaremos con mayor claridad en la Poética-, y, en tercer lugar, se debe emplear para distracción, para relajamiento y para descanso de la tensión).

Todas estas afirmaciones en torno a la música y su carácter ético-pedagógico y catárquico van a encontrar su eco en el pensamiento de Galeno de Pérgamo, quien insiste no solo en su utilidad para la ciencia médica, sino también en su influencia en la esfera anímica y emocional, en la misma línea de las tesis platónicas y especialmente aristotélicas.

\section{MEDICINA Y ESTÉTICA MUSICAL EN GALENO}

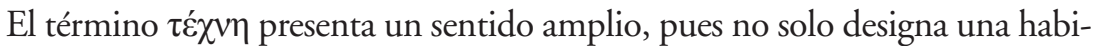
lidad o un oficio, sino que también apunta a una técnica que comprende un conjunto de reglas, un sistema o un método ${ }^{58}$. Es principalmente un saber hacer, entendiendo el cómo y el porqué, lo que conlleva un conocimiento profundo emanado de la experiencia $(\dot{\varepsilon} \mu \pi \varepsilon 1 \rho i ́ \alpha)^{59}$ :

${ }^{57}$ Pol., 1341 b 36-40.

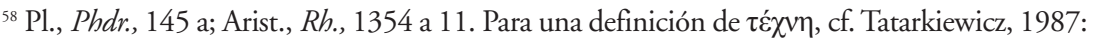
$39-43 ; 103-113$.

${ }^{59}$ Arist., EN., 1140 a 8-14. 


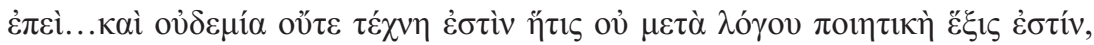

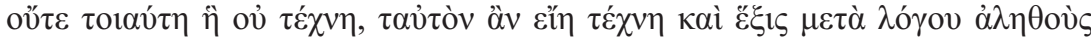

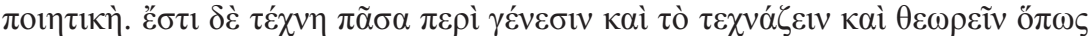

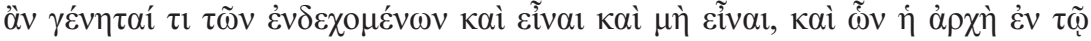

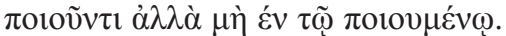

Puesto que ... no hay ningún arte que no sea una manera de ser productiva con la razón, ni una manera de ser tal que no sea un arte, serían lo mismo arte y manera de ser productiva con la razón verdadera. Todo arte es sobre una génesis y practicar un arte es considerar cómo se puede producir algo de lo que es posible ser y no ser, y cuyo principio está en quien lo produce, no en lo producido.

Galeno comparte con Aristóteles la idea de que la práctica de un arte está supeditada a la unión de un método general y una formación, los cuales garantizan una aptitud propicia para un eficaz desenlace ${ }^{60}$ :

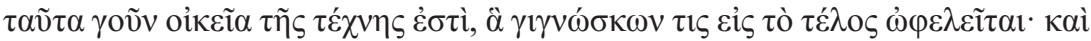

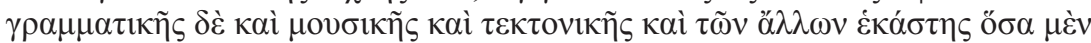

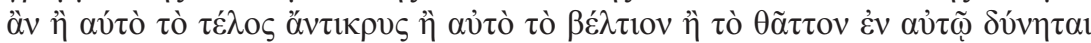

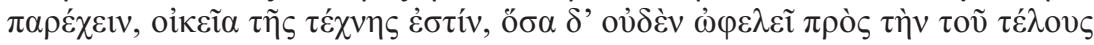

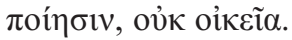

Por tanto, es propio del arte lo que uno, cuando lo conoce, utiliza para el fin. Todo aquello de la gramática, la música, la carpintería y de cada una de las demás que pudiese proporcionar directamente el mismo fin o lo mejor o lo más rápido en él, es propio del arte. Y cuanto no sirve para la consecución del fin, no es propio.

Sin embargo, hay que tener en cuenta que, aunque la aprehensión de un método requiera cierto tiempo, solo la práctica regular y constante asegura su afianzamiento $^{61}$ :

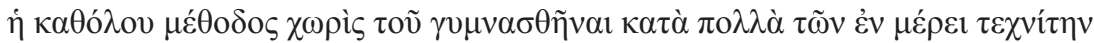

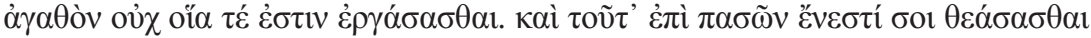

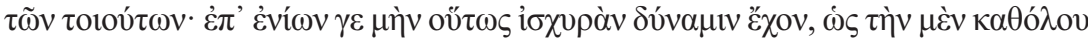

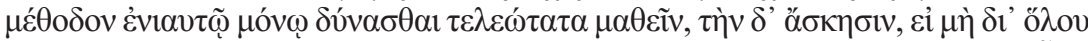

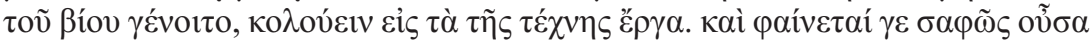

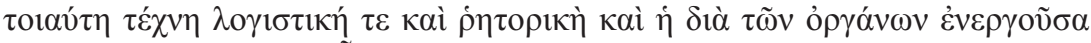

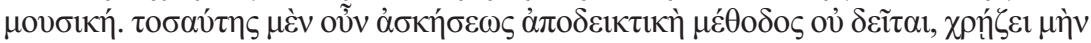

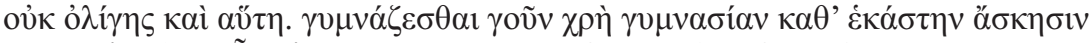

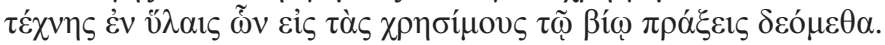

El método general, sin ser practicado, no puede producir en muchos de los casos particulares un buen practicante de un arte. Puedes observar esto en todas estas artes. En realidad, en algunas hay un poder tan fuerte que se podría aprender completamente el método general en un solo año, pero podría truncar la práctica para

${ }^{60}$ Trasybulus sive utrum medicinae sit an gymnasticae hygieine, 5. 858. 7-13 K.

${ }^{61}$ Gal., De placitis Hippocratis et Platonis, 5. 732. 15-733.8 K. 
los trabajos del arte, si ella no se diera a lo largo de la vida. Estas artes son claramente las matemáticas, la retórica y la música interpretada con instrumentos. Por tanto, un método apodíctico no precisa de una práctica así, sino que este requiere mucha. Ciertamente, es necesario ejercitarse de acuerdo con cada práctica de un arte en las materias que necesitamos para las acciones útiles de la vida.

En las artes ( $\tau \varepsilon \dot{\chi} \chi \alpha \imath)$ se complementan el método y el ejercicio, representados ambos por la mente y la mano respectivamente. Del mismo modo, la música depende de un sistema de aprendizaje, al tiempo que se revela como un arte manual donde la mano se convierte en su única vía de interpretación en los instrumentos. Este hecho no significa que sea solo una creación manual, sino que es el resultado de la inspiración, la cual se dirige de forma directa hacia el espíritu. Tal argumento conduce a Galeno a realizar la división entre artes liberales y artes serviles con la intención de destacar entre todas la medicina ${ }^{62}$ :

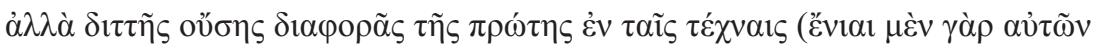

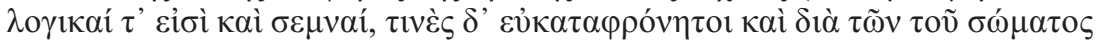

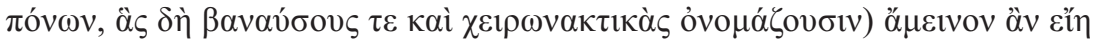

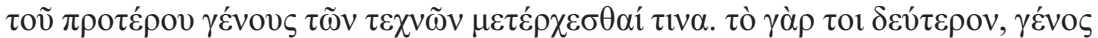

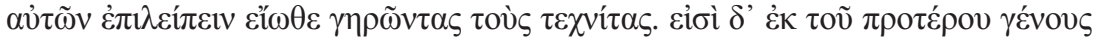

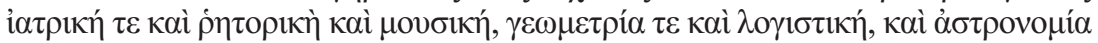

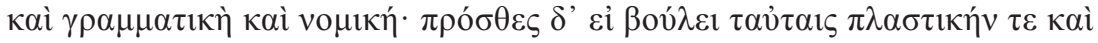
$\gamma \rho \alpha \varphi$

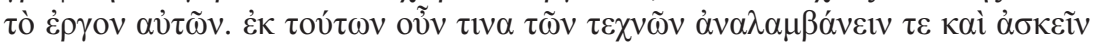

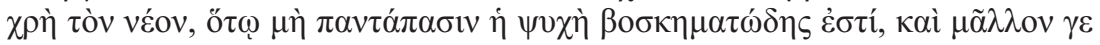

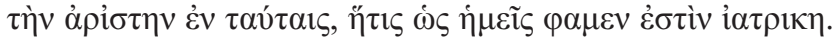

Pero ya que la primera diferencia entre las artes es que son de dos tipos (pues de ellas, unas son racionales y nobles, y otras desdeñables a causa de las fatigas del cuerpo, a las que denominan serviles y manuales), sería mejor que uno se ocupase de la primera clase de las artes. Pues los artesanos suelen dejar a un lado la segunda cuando son viejos. Pertenecen a la primera la medicina, la retórica, la música, la geometría, la lógica, la astronomía, la gramática y la jurisprudencia. Y, si quieres, añade a estas la escultura y la pintura. Pues, aunque sean eficaces gracias a las manos, sin embargo, su trabajo no requiere vigor juvenil. Por tanto, el joven, que no tenga en absoluto el alma embrutecida, debe elegir una de ellas y practicarla, y sobre todo la mejor entre ellas, la cual, como afirmamos, es la medicina.

Platón intuye esta clasificación galénica cuando describe tres clases de artes:

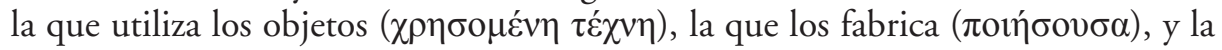
que los imita $(\mu \uparrow \mu \eta \sigma o \mu \varepsilon ́ v \eta)^{63}$. A ella se añade otra más compleja entre productiva

${ }^{62}$ Adhortatio ad artes addiscendas, $1.38 .12-39.10 \mathrm{~K}$.

${ }^{63}$ R., 601 d. Para las distintas divisiones de las artes en la Antigüedad, cf. Tatarkiewicz, 1987: 79-86. 


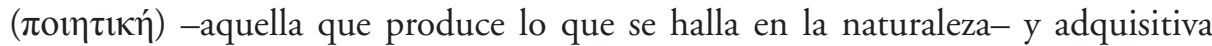

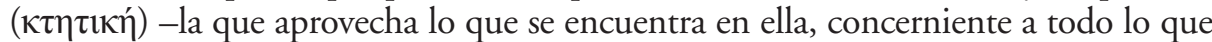
se aprende y al conocimiento-, ambas con sus pertinentes subtipos ${ }^{64}$.

Por su lado, Aristóteles, pese a su conformidad con esa diferenciación

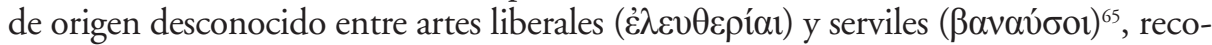
noce que, dentro de las primeras, es conveniente participar solo en aquellos trabajos útiles que no entorpezcan el desarrollo corporal, intelectual o anímico en su camino hacia la virtud ${ }^{66}$ :

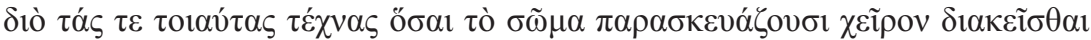

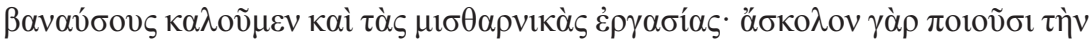

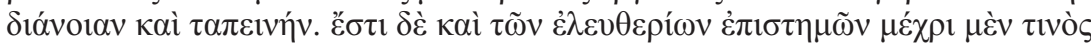

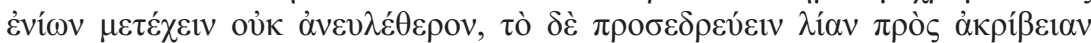

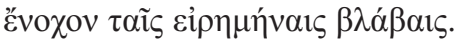

Por eso, llamamos vulgares a todas las artes que tienden a deteriorar el cuerpo, y también a los trabajos asalariados, pues hacen a la mente ociosa y vil. Y también entre las ciencias liberales, no es innoble participar de algunas hasta cierto punto, pero ocuparse en ellas con excesiva asiduidad y esmero supone los daños referidos.

Galeno secunda este planteamiento aristotélico, en el pasaje antes citado,

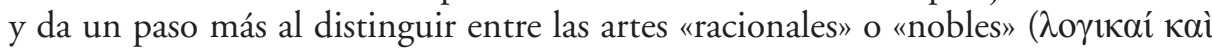

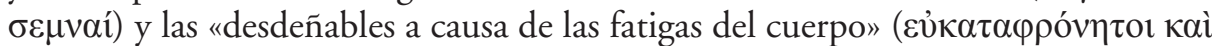

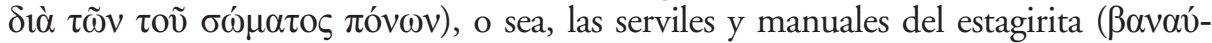

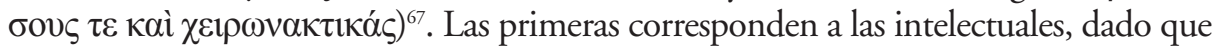
precisan de un esfuerzo mental por parte del hombre liberado de cualquier preocupación práctica para su subsistencia. Estas son la astronomía, la aritmética, la música y la geometría, entre otras. Por el contrario, las serviles o manuales se asocian a una operación física, como la escultura, la arquitectura o la pintura. Asimismo, el pergameno insiste en la relevancia de las manos, las cuales actúan bajo el dictado de la razón, pues no hay trabajo manual sin una tarea intelectual previa y solo así el arte resulta

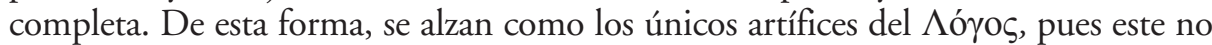
puede alcanzar su meta sin ellas, aunque el paso previo y principal sea la inteligencia ${ }^{68}$ :

${ }^{64}$ Sph., 219 a-c; 265 a-e.

${ }^{65}$ Pol., 1337 b 5-20. Cf. Pl., Lg., 817 e-818 a.

${ }^{6}$ Pol., 1337 b 11-17. No obstante, el filósofo rechaza la postura de los sofistas entre las útiles y las que proporcionan placer, y considera que todo arte realiza lo que la naturaleza es incapaz de terminar o imitar. Arist., Ph., 199 a 15-20. Cf. Po., 1448 a 1; 1460 a 7; a 8. Para las categorías de artes imitativas, cf. Po., 1447 a 12. Cicerón distingue entre oficios liberales y «sucios» (sordidi). Off., 42. 150-151.

${ }^{67}$ Cf. Tatarkiewicz, 1991: 318-319.

${ }^{68}$ De usu partium, 3. 5. 8-6. $2 \mathrm{~K}$. Cf. De tremore, palpitatione, convulsione et rigore, 7. 606. 2-7 K:

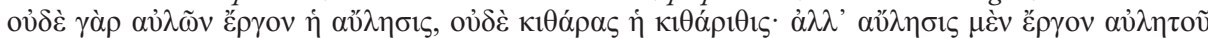

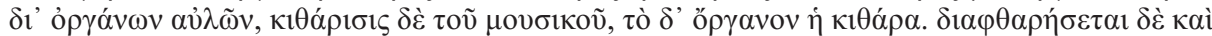

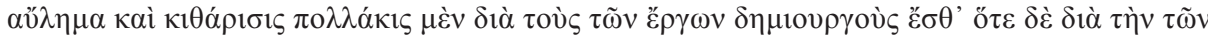




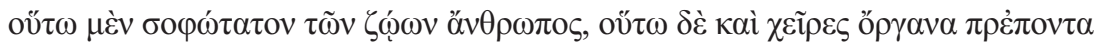

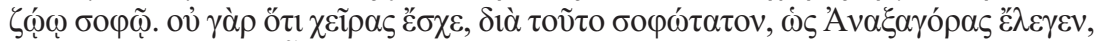

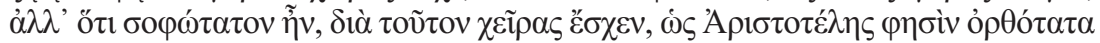

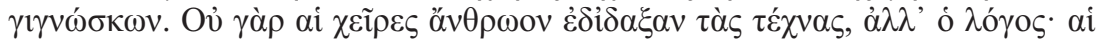

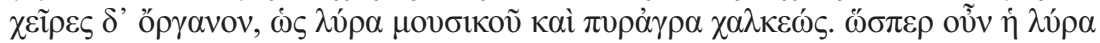

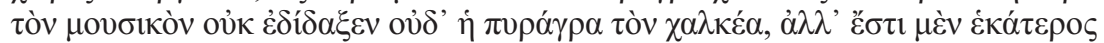

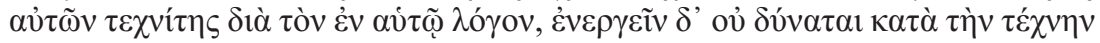

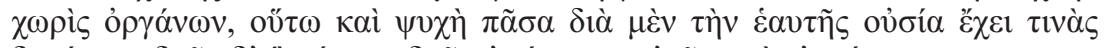

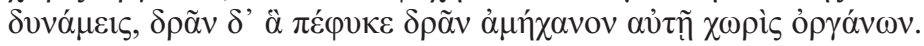

Así el hombre es el más inteligente de los seres vivos, y de esta manera también las manos son instrumentos apropiados para un ser vivo inteligente. Pues no porque tenía manos fue por esto el más inteligente, como decía Anaxágoras ${ }^{69}$, sino, porque era el más inteligente, por esto tenía manos, como asegura Aristóteles, ya que conoce lo más correcto. Pues las manos no han enseñado las artes al hombre, sino la razón, y las manos son su instrumento, como una lira del músico y unas tenazas del herrero. Por tanto, así como la lira no ha enseñado al músico ni las tenazas al herrero, sino que cada uno de ellos es un artífice debido a la razón que hay en su interior, pero no puede trabajar según su arte sin instrumentos, así también toda alma, por su propia esencia, tiene algunas facultades, pero no le es posible hacer sin instrumentos lo que es natural.

En atención a las artes liberales o racionales, Galeno, en su defensa de la medicina, reprocha a la sociedad de su tiempo su menosprecio hacia aquellas, a las que él juzga de auténticas ciencias ${ }^{70}$ :

$\alpha$

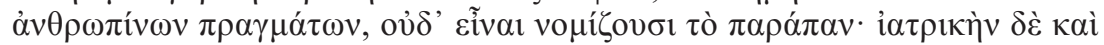

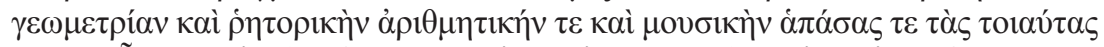

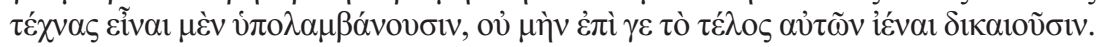

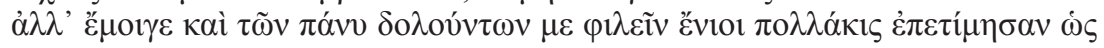

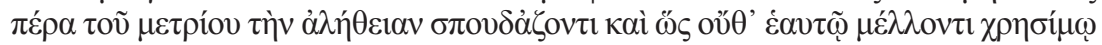

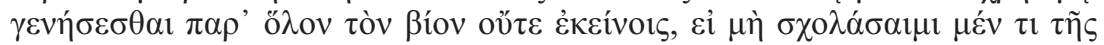

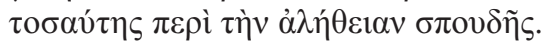

Pues no creen en absoluto que esa, la primera y verdadera sabiduría, ya que es ciencia de cosas divinas y humanas, lo sea. Aprueban que son artes la medicina, la geometría, la retórica, la aritmética, la música y todas las similares, pero no consideran justo llegar al final de ellas. Sin embargo, algunos de los que parecen apreciarme

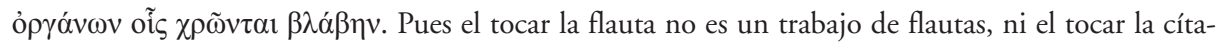
ra de una cítara, sino que tocar la flauta es una actividad del flautista a través de los instrumentos de las flautas, y el tocar la cítara del músico, y el instrumento es la cítara. Pero el sonido de la flauta y el de la cítara se rompen muchas veces por culpa de los ejecutores de sus actos, pero hay veces que es debido al defecto de los instrumentos que utilizan.

${ }^{69}$ Cf. Arist., $P A$., 687 a 7-18; 687 b.

${ }^{70}$ De methodo medendi, 10. 2. 5-15 K. Cf. De usu partium, 3. 837. 1-838. 2 K. 
a menudo me han criticado por ocuparme de la verdad más allá de lo tolerable y porque no voy a ser útil ni para mí mismo en toda mi vida ni para ellos, si no estuviera libre de tal afán por la verdad.

Dicha censura también se extiende a aquellos que se valen de las artes liberales -algunas de las cuales son parte esencial de la educación de un médico ${ }^{71}$ - para su interés personal en pos de riquezas y adulación ${ }^{72}$ :

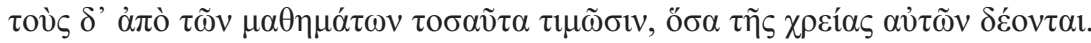

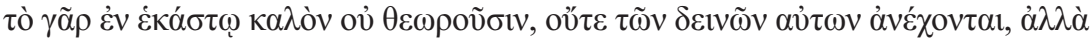

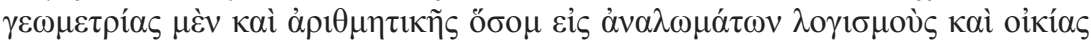

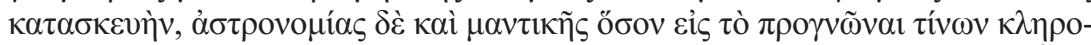

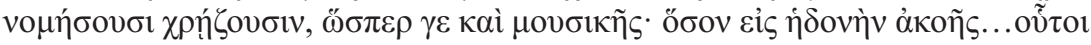

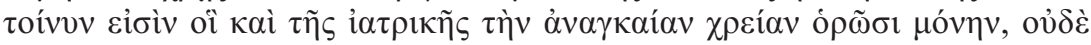
$\tau \alpha \dot{\tau} \tau \vee$ ỏ $\rho \tilde{\omega} \varsigma$.

Estiman a los hombres a partir de sus enseñanzas tanto cuanto requieren para su propio beneficio. Pues no ven lo hermoso en cada uno, ni soportan a los admirables, sino que utilizan la geometría y la aritmética para los cálculos de sus dispendios y el arreglo de su vivienda, y la astronomía y la mántica para conocer antes de quiénes van a heredar, como también la música, para placer de su oído ${ }^{73}$... Así pues, ellos son los que ven solo la utilidad necesaria de la medicina, no la auténtica.

El blanco de esta repulsa hacia estas egregias prácticas es encabezado por el metódico Tésalo de Trales $(c a .70-95 \text { d. C. })^{74}$, quien era reprobado en Roma por afirmar que los médicos no precisaban de las ciencias nobles ni tampoco de demasiada experiencia y hábito para ejercer su profesión ${ }^{75}$ :

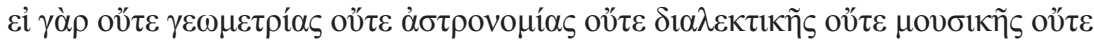

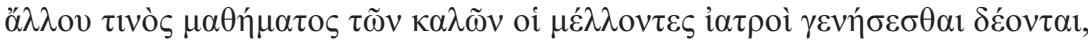

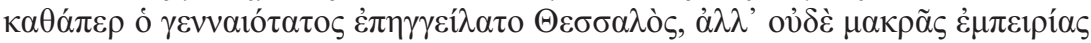

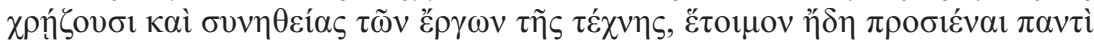
$\gamma \varepsilon v \eta \sigma o \mu \varepsilon \dot{v} \omega \dot{\rho} \alpha \dot{\alpha} \delta \dot{\omega} \omega \zeta$ i $\alpha \tau \rho \tilde{\omega}$.

Pues si los que están dispuestos a convertirse en médicos no necesitan la geometría ni la astronomía ni la dialéctica ni la música ni ningún otro aprendizaje de las

${ }^{71}$ La música, como las matemáticas, la geometría, la astronomía, constituyen para Galeno disciplinas básicas en la formación de un médico. Cf. Hp., Aër., 1-2 L. Deichgräber, 1970: 94; 100-107; Alby, 2004: 13-17.

${ }^{72}$ De praenotione ad Posthumum (Epigenem), 14. 604. 9-605. 9 K. Cf. Tac., Dial., 29; Amm., 28. 4.

${ }^{73}$ Sen., Epist., 88. 9-11.

${ }^{74}$ De methodo medendi, 10. 17. 14-18 K. La escuela metódica seguía los preceptos de Demócrito y Epicuro y, en cuanto a la teoría de los átomos y los poros, distinguía dos estados del cuerpo humano, uno estricto y otro laxo, a causa de la relajación o estrechez de los poros. Cf. Scott, 1991: 106-110.

${ }^{75}$ De methodo medendi, 10. 5. 1-8 K, en especial 10. 5. 4-9. 
ciencias nobles, según el muy magnánimo Tésalo, y ni tampoco se sirven de una larga experiencia y hábito en los actos del arte, ya está resuelto para todo el que vaya a ser médico acercarse fácilmente a ella.

Sin embargo, independientemente de que el arte sea servil o liberal, nuestro médico resalta que todo practicante, para llegar a ser ducho en cualquiera de ellas, no solo debe invertir tiempo, sino que incluso ha de ser conocedor tanto de lo unitario y lo ilimitado como de sus partes y cualidades ${ }^{76}$. Solo así logrará alcanzar el máximo estatus de técnico ${ }^{77}$. Tal postura es ilustrada con un pasaje de Platón ${ }^{78}$ donde se toman como paradigma dos disciplinas liberales, la gramática y la músi$\mathrm{ca}^{79}$. En esta última, aunque la voz es solo una, la cantidad de los tonos y sonidos (graves, agudos e intermedios), el número de los intervalos, sus combinaciones, las armonías, los ritmos y los metros constituyen sus propiedades, cuyo conocimiento corresponde al experto ${ }^{80}$ :

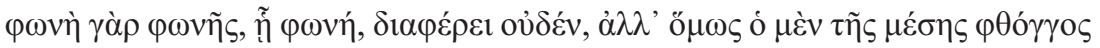

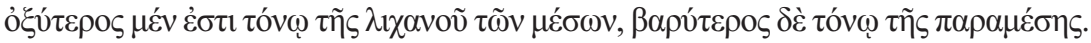

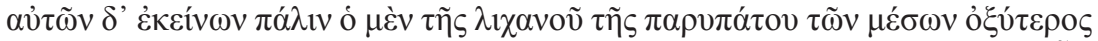

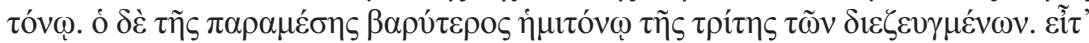

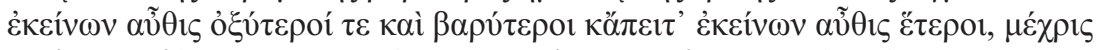

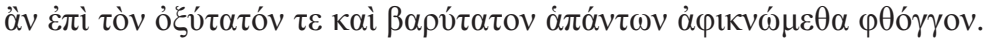

Pues una voz de otra, según lo que es voz, en nada se diferencia, y sin embargo el sonido de la mésé es un tono más agudo que la lichanós mesôn, y un tono más grave que la paramésé. Por el contrario, entre ellos mismos, el sonido de la lichanós es un tono más agudo que la parhypátos mesôn, y el de la paramésē es un semitono más grave que la trité diezeugménôn. Luego, unos son más agudos y más graves que otros, y otros lo son respecto a estos, hasta que lleguemos al sonido más agudo y al más grave de todos ${ }^{81}$.

${ }^{76} \mathrm{Cf}$. Trasybulus sive utrum medicinae sit an gymnasticae hygieine, 5. 850. 16-851. $11 \mathrm{~K}$. Realmente Galeno considera que las artes, como la retórica, la aritmética, la geometría y la música, no poseen una sola técnica. Por ello, a causa de su magnitud, la mayoría de los practicantes no pueden llegar a un conocimiento total, de suerte que, si una misma persona fuera a la vez aritmético, gramático y filósofo, se podría pensar que estas actividades participan de una única técnica.

${ }^{77}$ Adversus Lycum, 18a. 209-211 K.

${ }_{78}$ Phlb., 17 b. Cf. Gal., De placitis Hippocratis et Platonis, 5. 755. 2-756. 13 K.

${ }^{79}$ Aristóteles integra la actividad musical en el grupo de las serviles, debido al hecho de que, en las competiciones, el ejecutante piensa en el placer de los oyentes, no en el suyo propio, como corresponde a la postura hedonista del filósofo ante la música. Por tanto, aquel tipo de placer es vulgar y pertenece al hombre que está sometido a un salario, resultando ser un vulgar artesano sometidos a las demandas del público. Pol., 1341 b 9-18.

${ }^{80}$ Gal., Adversus Lycum, 18a. 215. 11-216. $1 \mathrm{~K}$.

${ }^{81}$ Los nombres de las notas designan las cuerdas en el siguiente orden desde la más aguda: hypatē, parhypátē, lichanós, mésé (media), paramésé, tríté, paranetē y netē. Aristid. Quint., 1. 8. 40-58. Cf. Jan 1965: 420-421; Winnington-Ingram, 1968: 10-47; Landels, 1999: 86-109; Hagel, 2009: 1-8. Cf. Boeth., Mus., 1. 20. 
El razonamiento de Galeno es aplicable a todas las ramas del saber, como la gramática con las letras o la pintura con los colores ${ }^{82}$. Realmente su propósito con esta exposición es desacreditar a Lico ${ }^{83}$ por su total desconocimiento del verdadero oficio médico y, en especial, por su atrevimiento a criticar a su muy admirado Hipócrates ${ }^{84}$.

En referencia a la medicina, el pergameno se cuestiona si es un arte o una ciencia $^{85}$. Antes de llegar a una respuesta, esboza algunas teorías. Si para los lógicos, como Erasístrato ${ }^{86}$, aquella solo es en parte ciencia, en relación a los dominios de la etiología y al conocimiento de la naturaleza, y en parte conjetura de la terapéutica y la semiología, para los metódicos es enteramente una ciencia ${ }^{87}$. En cambio, si un arte es una unión coherente de concepciones y nociones, organizadas de una determinada manera y con ciertas proporciones, que persiguen una meta útil en la vida, Galeno considera que la medicina, al estar provista de ideas relativas al hombre, ha de ser llamada arte, de acuerdo con la definición anterior y porque tiende hacia una clase de utilidad en la vida: salvar, curar y preservar la salud ${ }^{88}$. Tal noción lo lleva a distinguir dos tipos de artes: las que llegan al fin que se ajusta a sí mismas -como la carpintería, la construcción naval o la arquitectura-, y las que apuntan a su objetivo, pero no siempre lo encuentran, por lo que reciben el apelativo de conjeturales

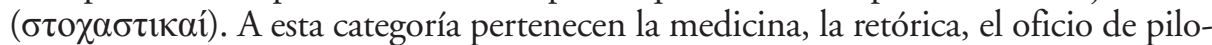
tar una nave y el tiro con arco ${ }^{89}$.

Nuestro médico también subraya otra doble diferencia ${ }^{90}$. Unas, pues, existen mientras tienen vigencia, de modo que, cuando acaba su actividad, no se ve logro alguno ( $\dot{\alpha} \pi 0 \tau \dot{\lambda} \lambda \varepsilon \sigma \mu \alpha)$, como el arte de la danza, de la cítara, la lucha y todas las musi-

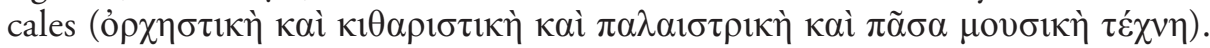

${ }^{82}$ Cf. Adversus Lycum, 18a. $214 \mathrm{~K}$.

${ }^{83}$ Se trata de Lico de Macedonia, médico anatomista, contemporáneo de Galeno, quien escribió sobre los músculos. Cf. Kind ,1927: 2408-2417; Towaide, 2005: 937-940.

${ }^{84}$ Cf. Gal., Adversus Lycum, 18a. 196-245 K.

${ }^{85}$ Cf. Gal., Ars medica, 1. 307 K. Galeno, a este respecto, retoma la tradicional distinción aristotélica. Cf. Arist., EN., 1139 b 14-1141 b 8; Met., 980 a 22-982 a 22; 981 b 20-23; 26-28. Para una definición de la medicina como $\tau \dot{\chi} \chi v \eta$, cf. Alby 2004: 5-29, en especial, 10-12, donde se describe con cuatro criterios, a la luz del Corpus hippocraticum: universalidad, posibilidad de ser transmitida

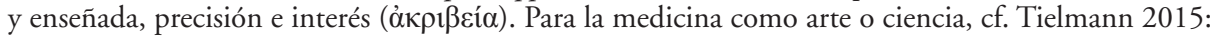

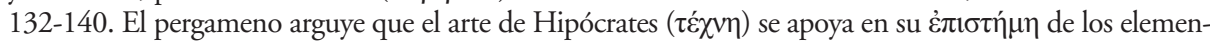
tos físicos. Gal., In Hippocratis de natura hominis, 15. 15. 14-16. 5. K.

${ }^{86}$ Médico anatomista de Yúlide, en Ceos (304-250 a. C.), fundador, junto a Herófilo, de la escuela médica de Alejandría. Destacó por su creencia de que el corazón es el centro y punto de partida de los sistemas arterial y venoso, y de que las arterias y las venas tenía interconexiones muy finas. Cf. Nutton, 2004: 13-15.

${ }^{87}$ Introductio seu medicus, $14.684 .11-19 \mathrm{~K}$.

${ }^{88}$ Introductio seu medicus, 14. 685. 3-12 K.

${ }^{89}$ Introductio seu medicus, 14. 685. 13-686. $1 \mathrm{~K}$.

${ }^{90}$ Introductio seu medicus, 14. 686. 1-13 K. 
Junto a ellas, hay otras que, sin ser un trabajo propiamente dicho, mientras actúan, preparan la llegada de su resultado, el cual se manifiesta después de haber cesado la acción, de suerte que sus obras quedan para el futuro, como la escultura, la pintura, la arquitectura y, por supuesto la medicina. En esta última, el paciente, durante el tratamiento -momento justo en el que se está combatiendo la enfermedad-, no ve efecto alguno, sino que solo consigue recuperarse y gozar de buena salud tras

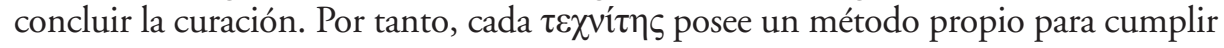
con sus expectativas ${ }^{91}$ :

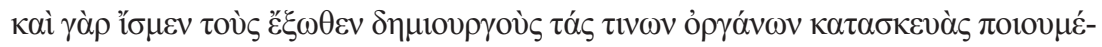

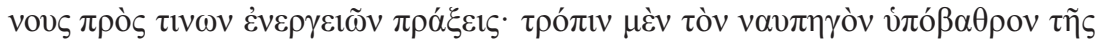

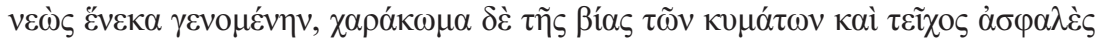

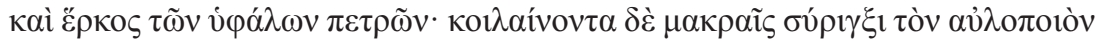

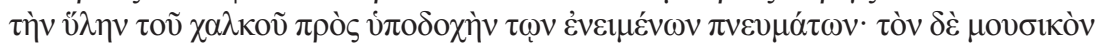

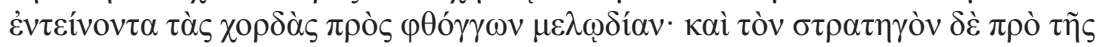

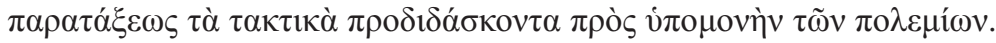

Pues sabemos que los que trabajan desde fuera llevan a cabo los arreglos de unos instrumentos para las realizaciones de ciertos actos, pues, por un lado, la quilla es el sostén armador para la nave, y, por otro, un rompeolas para la fuerza de las olas, y un muro seguro y una barrera para las rocas que están debajo del mar; el fabricante de flautas ahueca la materia del bronce en largas cañas para recibir los soplos que pasan por dentro; el músico tensa las cuerdas para la melodía de los sonidos; el médico prepara los fármacos sanadores para aliviar los dolores, y el general enseña las tácticas antes del combate para resistir a los enemigos.

Ahora bien, si el fin y la actividad expiran al mismo tiempo en la música, ¿cómo esta es capaz de afectar a la voluntad? De acuerdo con la visión de Posidonio ${ }^{92}$, las personas que siguen las alteraciones del alma no viven conforme a la naturaleza, puesto que se dejan llevar por su parte irracional. Contrariamente, las que abrazan los dictados de la esfera natural, atienden su parte racional y no las afecciones. Por ello, una vez descubierta la causa de estas, es fundamental conocer métodos de entrenamiento. Como principal recurso, según estipularon antes los pitagóricos, Damón ${ }^{93}$, Platón o Aristóteles, Galeno prescribe un régimen de ritmos, escalas y ejercicios, dado que cree en la capacidad de la música para influir en la parte irracional y la noble del alma. Para esclarecer esta idea, recuerda la conocida anécdota del joven ebrio ${ }^{94}$ :

${ }^{91}$ An animal sit quod est in utero, 19. 168. 18-169. $9 \mathrm{~K}$.

${ }^{92}$ Posid., frag. 150 b Edelstein-Kidd =Gal., placitis Hippocratis et Platonis, 5. 471. 11-17 K; 161 Edelstein-Kidd =Gal., placitis Hippocratis et Platonis, 5. 472-3-13 K; 168 Edelstein-Kidd=Gal., placitis Hippocratis et Platonis, 5. 472.2-473. $17 \mathrm{~K}$.

${ }^{93}$ Frag. A 8. 1-4 DK.

${ }^{94}$ De placitis Hippocratis et Platonis, 5. 473. 3-13 K. 


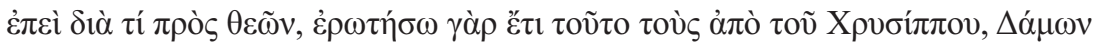

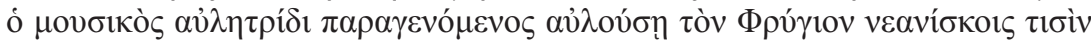

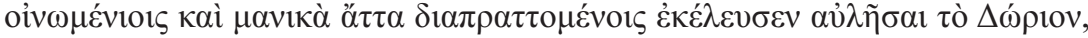

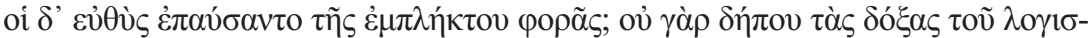

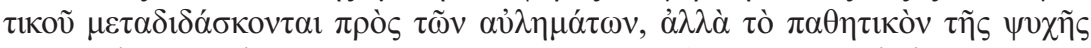

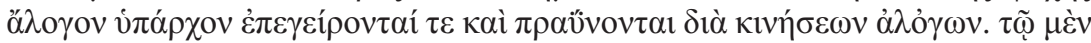

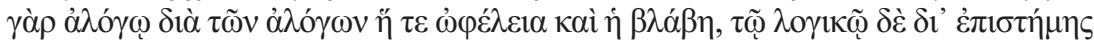
$\tau \varepsilon \kappa \alpha i ̀ ~ \alpha \mu \alpha \theta i ́ \alpha s$.

¿Por qué, por los dioses, -pues voy a preguntar esto incluso a los seguidores de Crisipo- Damón el músico, cuando se acercó a una flautista que tocaba el modo frigio a unos jóvenes que estaban ebrios y haciendo locuras, le dijo a ella que tocara el modo dorio, y los jóvenes depusieron al instante su insensato comportamiento? Pues no se les enseña a cambiar las opiniones de su facultad racional con las piezas de la flauta, sino que al ser irracional la parte afectiva del alma, ellos se reaniman y se calman por medio de movimientos irracionales. Pues lo irracional encuentra el auxilio y el daño por medio de cosas irracionales, y lo racional mediante conocimiento e ignorancia.

El pergameno, sobre la base de sus antecesores, con quienes su pensamiento gana autoridad, confía en el poder mimético, catárquico y pedagógico de las melodías con la pretensión de abogar por una educación musical en los jóvenes. Admite la existencia de una predisposición innata a la música y la gimnasia, de manera que ambas disciplinas constituyen una parte relevante de la $\pi \alpha 1 \delta \varepsilon i ́ \alpha$, dada su repercusión en el alma y el cuerpo, respectivamente, desde la infancia ${ }^{95}$ :

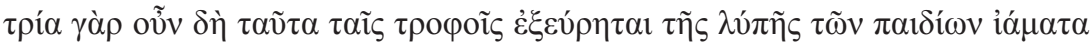

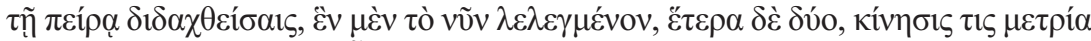

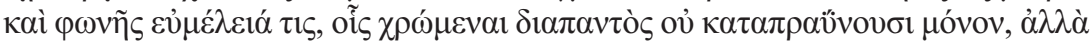

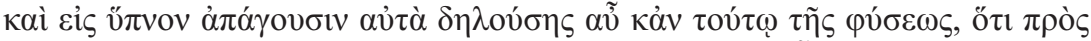

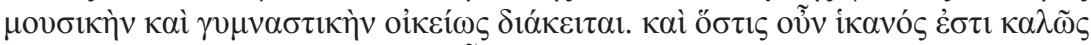

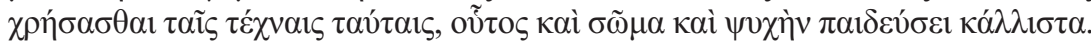
Las nodrizas, instruidas mediante la experiencia, han descubierto estos tres remedios para la pena de los niños: uno es el que acabamos de exponer, y los otros dos consisten en un movimiento moderado y en cierta modulación de la voz, empleando dos gestos con los que ellas no solo logran siempre calmarlos, sino que incluso los duermen, de modo que con esto la naturaleza demuestra que están predispuestos íntimamente a la música y a la gimnasia. Quien sea capaz de utilizar correctamente estas artes, educará de la mejor manera su cuerpo y su alma.

Como fruto de su preocupación por la salud corporal y anímica, sugiere un plan dietético en el que se debe evitar todo exceso en cualquier ámbito, incluidos

${ }^{95}$ Gal., De sanitate tuenda, 6. 36. 17-37. 7 K. Cf. Grimaudo, 2008: 200-204. 
los dos anteriores, pues este implica una alteración que desemboca en la enfer$\operatorname{medad}^{96}$ :

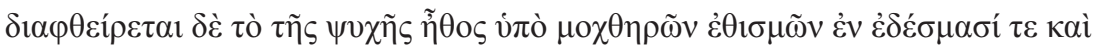

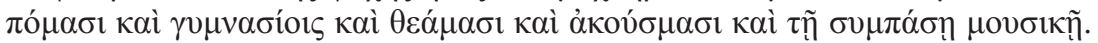

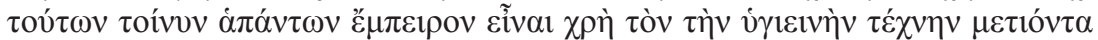

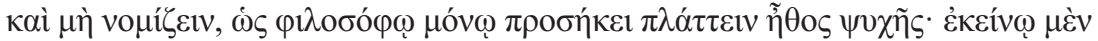

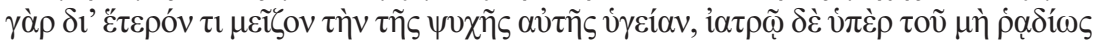

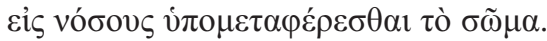

El hábito del alma se corrompe por malas costumbres en la comida, bebida, ejercicios, espectáculos, audiciones y música en general. La persona dedicada al arte de la salud debe ser experta en todos estos temas y no pensar que solo concierne al filósofo moldear el hábito del alma, pues de aquél depende la salud de la misma alma, entre otros aspectos más, y del médico, que el cuerpo no caiga fácilmente en enfermedades.

Así, cobra significación la figura del médico-filósofo, según el postulado de la escuela hipocrática ${ }^{97}$ a fin de lograr el equilibrio entre el alma y el cuerpo para la consecución de la salud ${ }^{98}$. Por tanto, Galeno, lo mismo que Platón ${ }^{99}$, persevera en la integración de la gimnasia y la música en la instrucción de los jóvenes, habida cuenta de su impacto positivo a nivel corporal y anímico. A ello, también se suma la práctica de las ciencias (liberales) a cualquier edad, como un método para evitar el mal y tomar el camino de la virtud ${ }^{100}$ :

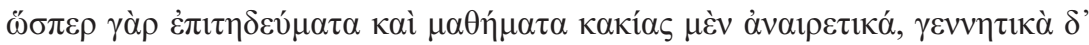

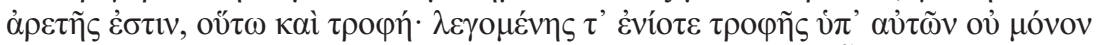

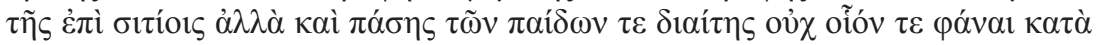

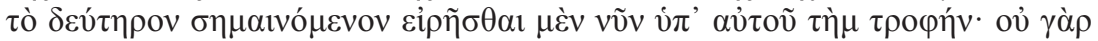

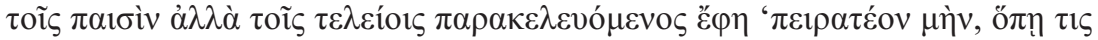

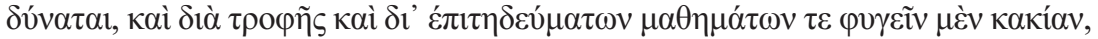

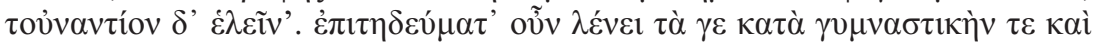
$\mu$

Pues al igual que las formas de vida y las ciencias destruyen la maldad y con engendradoras de la virtud, así también la alimentación. Aunque ellos denominan algunas veces alimentación no solo a los alimentos, sino incluso a toda dieta de los niños, no es posible decir que ahora se refiere a la alimentación según el segundo significado, pues cuando se dirige no a los niños, sino a los adultos, dice que «se debe

\footnotetext{
${ }^{96}$ De sanitate tuenda, 6. 40. 4-11 K.

${ }^{97}$ Hp. Decent., 5. 1-8.

${ }^{98}$ Cf. Gal., Quod optimus medicus sit quoque philosophus, 1. 53. 1-63. 4 K. Rodríguez, 2014: 265-278; Ieraci, 1987: 147-163; Ieraci, 1991: 133-151; Pigeaud, 1998: 295-331.

99 Ti., 87 b.

${ }^{100}$ Quod animi mores corporis temperamenta sequntur, 4. 813. 4-15 K.
} 
intentar, en la medida de lo posible, huir del vicio mediante la alimentación, las formas de vida y las ciencias, y escoger lo contrario». Así pues, llama formas de vida a los temas relativos a la gimnasia y la música, y ciencias a los de la geometría y la aritmética.

En otro pasaje, nuestro médico emplea, dentro de un mismo contexto, las denominaciones de «buen estado físico» ( $\varepsilon \dot{\varepsilon} \varepsilon \xi i ́ \alpha)$ y «constitución natural» ( $\left(\xi_{\xi 1 \zeta)}\right.$ para referirse, respectivamente, a la salud y la inclinación hacia las ciencias, como una predisposición innata, estable y, por supuesto, saludable. En ellas, sobre todo, en las intelectuales, intervienen manos, inteligencia y razón, como se expuso anteriormente ${ }^{101}$ :

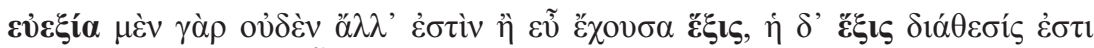

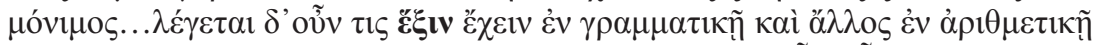

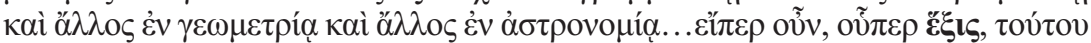

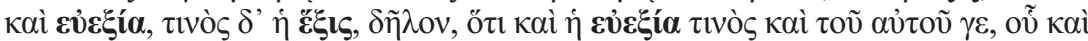

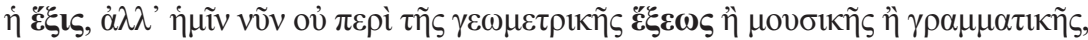

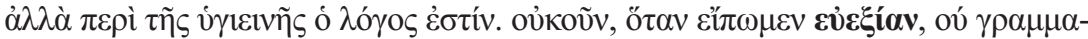

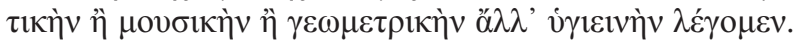

Pues un buen estado físico no es nada más que una buena constitución natural, pero la constitución natural es un estado estable ... Por tanto, se dice que uno tiene una constitución en la gramática; otro, en la aritmética; otro, en la geometría, y otro, en la astronomía ... Así pues, si un buen estado físico es de la misma persona a la que pertenece una constitución natural, pero la constitución natural es de alguien, es evidente que también el buen estado físico lo es de alguien y del mismo al que también pertenece la buena constitución. Pero la exposición es sobre la salud. Por tanto, cuando hablamos de buen estado físico, no nos referimos a la gramática, la música o la geometría, sino a la salud.

Estos dos términos son complementarios en cuanto que una constitución sana presenta una propensión al estudio de las ciencias, entre las cuales Galeno califica la música. Por tal motivo, considera fundamental la inclusión de esta disciplina en la educación reglada de los jóvenes, e incluso va más allá, dado que puede tener aplicaciones en la medicina, aun distintas a las que estimaban en su momento los pitagóricos, pese a la opinión de otros ${ }^{102}$ :

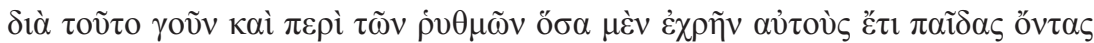

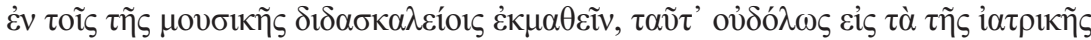

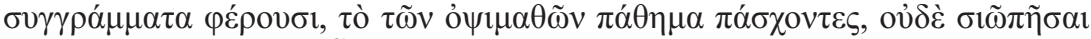

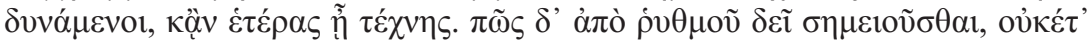

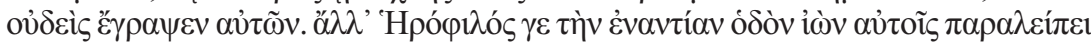

${ }^{101}$ Trasybulus sive utrum medicinae sit an gymnasticae hygieine, 5. 824. 10-825. 6 K. Cf. De usu partium, 3. 5. 8-6. $2 \mathrm{~K}$.

${ }^{102}$ De dignoscendis pulsibus, 8. 871. 13-872. $3 \mathrm{~K}$. 


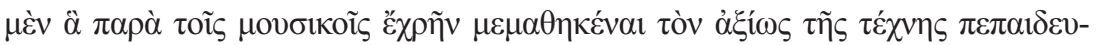

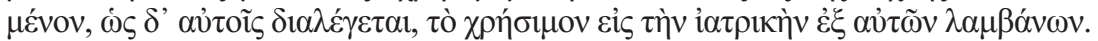
Por consiguiente, debido a esto y sobre los ritmos que ellos debían aprender en las escuelas de música cuando aún eran niños, difícilmente los incluyen en los libros de medicina, de modo que padecen la experiencia de los que comienzan a aprender demasiado tarde y no pueden callar, aunque pertenezca a otro arte. Y ninguno de ellos escribió cómo se debe indicar a partir de un ritmo. No obstante, Herófilo ${ }^{103}$, al emprender el camino contrario a estos, omite, por un lado, lo que era necesario que la persona apropiadamente instruida en el arte hubiese aprendido de los músicos, pero, por otro, que dialoga con ellos, tomando lo útil para la medicina a partir de ellos.

Dentro de esos usos médicos antes aludidos, el pergameno marca la sincronía entre los pulsos y los ritmos ${ }^{104}$ :

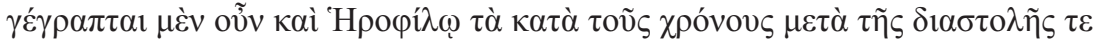

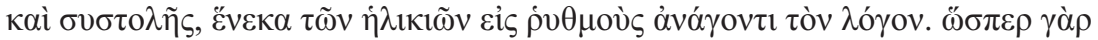

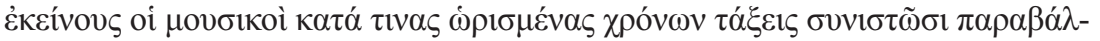

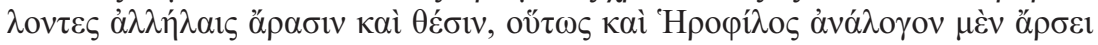

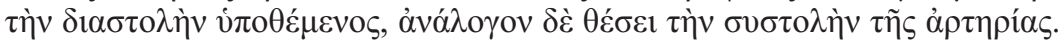
Así pues, Herófilo, además, escribió lo relativo a los tiempos en la diástole y la sístole, atribuyendo el argumento a los ritmos debido a las edades. Pues de la misma manera que los músicos conforman aquellos según algunas órdenes establecidas de tiempos, al comparar arsis y tesis con unas y otras, así también Herófilo, al suponer que la diástole es análoga a la arsis, y que la sístole de la arteria es análoga a la tesis.

Ciertamente, aunque achaca a Herófilo la observación de la correspondencia entre arsis/tesis y pulsos, especifica el funcionamiento de los ritmos de estos bajo el criterio de los músicos ${ }^{105}$ :

${ }^{103}$ Médico de Calcedonia (340/35-280 a. C.), cofundador, junto a Erasístrato, de la escuela médica de Alejandría. Destacó por sus estudios sobre anatomía humana a partir de disecciones humanas, en concreto de criminales. Para él, las pulsaciones eran debidas a los movimientos de contracción y dilatación de las arterias, aunque no consideró que la sangre circulaba por ellas gracias al bombeo del corazón. Inventó un tipo de clepsidra portátil para medir las pulsaciones. Cf. Stade, 1989; Towaide, 2005: cols. 274-276.

${ }^{104}$ Synopsis librorum suorum de pulsibus, 9. 463. 15-464. 4 K. Cf. De dignoscendis pulsibus,

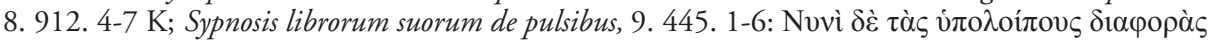

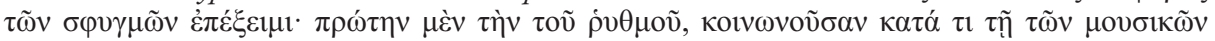

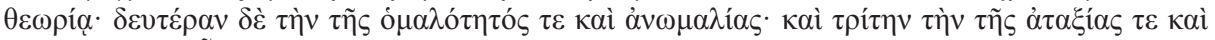

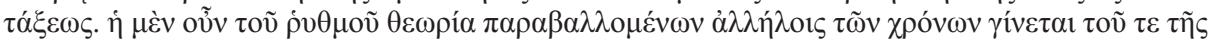
$\delta 1 \alpha \sigma \tau 0 \lambda \tilde{\eta} \varsigma \kappa \alpha i ̀ ~ \sigma v \sigma \tau 0 \lambda \tilde{\eta} \varsigma$. Ahora voy a explicar las diferencias restantes de los pulsos: la primera es la del ritmo, la cual guarda relación con la teoría de los músicos; la segunda es la diferencia de la regularidad y la anomalía, y la tercera es la de desorden y orden. Así pues, la del ritmo es una teoría de los tiempos que se comparan unos con otros, el de la diástole y la sístole.

${ }^{105}$ De differentia pulsuum, 8. 517. 3-10 K. 


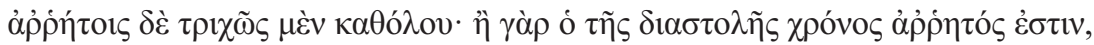

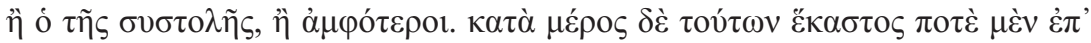

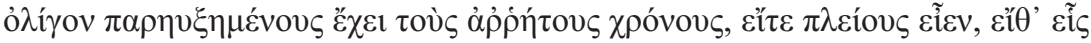

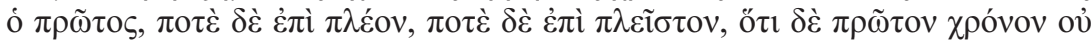

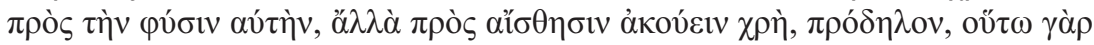

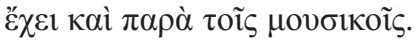

(El ritmo) con pulsos inconstantes presenta tres formas en total: o el tiempo de la diástole es inconstante, o el de la sístole o el de ambos. Unas veces, cada uno de estos tiene sucesivamente los tiempos inconstantes un poco aumentados, bien sean muchos, bien sea uno el primero, otras veces más, y otras en exceso. Es evidente que debemos oír un tiempo primero no por la misma naturaleza, sino por el sentido. Pues así es también para los músicos.

Con esta explicación procura ensalzar el oído del facultativo, al igual que el del músico, pues ambos están dotados de esa sensibilidad especial capaz de percibir lo más pequeño, gracias a su formación y a las excelencias de su arte, como sucede en los pulsos ${ }^{106}$ :

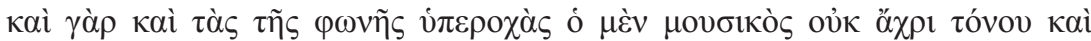

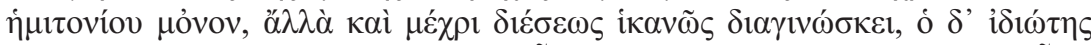

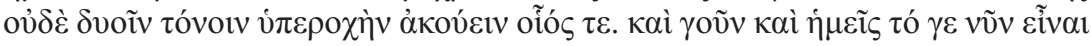

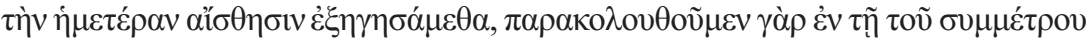

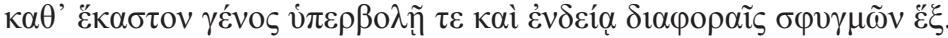

Pues también el músico reconoce suficientemente las subidas del sonido no solo hasta un tono y un semitono, sino incluso hasta un cuarto de tono, mientras que el hombre corriente no es capaz de oír la subida de dos tonos. Así pues, también nosotros hemos indicado que lo de ahora es nuestra percepción, pues percibimos seis diferencias de pulsos en el exceso y carencia del moderado en cada clase.

En resumidas cuentas, para el pergameno, médicos y músicos, junto a oradores, gramáticos y filósofos, son oficios liberales, a los que se unen geómetras y astrónomos, entre otros ${ }^{107}$. Todos hacen un uso correcto de la palabra para, en sus definiciones, ilustrar la verdad de sus artes, porque "la enfermedad de la "filoristía" devora no solo a médicos y filósofos, sino también a oradores, músicos y gramáticos»

${ }^{106}$ De differentia pulsuum, 8. 620. 2-8 K. Cf. De differentia pulsuum, 8. 618. 14-620. K.

${ }^{107}$ Cf. I. 44.10-45. $1 \mathrm{~K}$. Asimismo, establecen fuertes lazos con los alumnos, a los que transmiten, además, que, aunque confíen en sus criterios naturales, no se aparten del juicio (...' $\alpha \lambda \lambda$ ' oư $\chi \grave{~}$

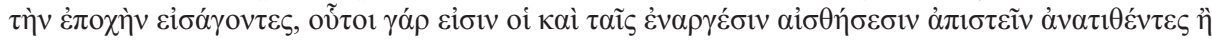

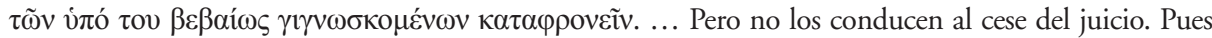
ellos son los que imponen desconfiar de las percepciones manifiestas o despreciar lo que se conoce con certeza). 


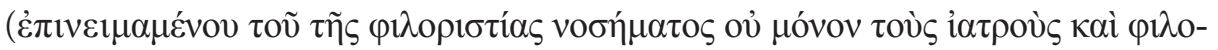

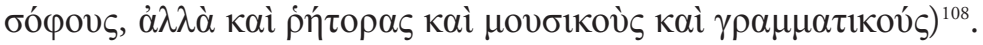

\section{CONCLUSIÓN}

De todos estos testimonios se colige la existencia en Galeno de una estética musical basada en el pensamiento platónico y aristotélico. Nuestro médico se sirve continuamente de las teorías a este respecto de los antiguos filósofos con la intención de reforzar sus propias nociones acerca de la música y su conexión con la práctica médica. Evoca la idea aristotélica de que todo arte requiere una formación y un método, representados ambos por manos y mente respectivamente. Por consiguiente, retoma la clasificación de Aristóteles entre las artes serviles y las liberales o intelectuales, dentro de las cuales inserta la medicina y la música. En el caso concreto de esta última, el intelecto y la inspiración actúan como recursos imprescindibles para su ejecución a través de las manos, las cuales ocupan un segundo plano, al no intervenir en el proceso creativo sino en la interpretación.

Un segundo punto en común de estas dos disciplinas responde al hecho de que pueden ser cultivadas a cualquier edad, dado que no precisan de fuerza, frente a las serviles o manuales, las cuales obedecen al vigor físico.

No obstante, el pergameno señala una diferencia notable entre la actividad

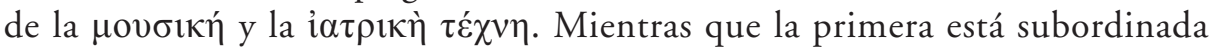
a su vigencia, de forma que su objetivo termina con su misma actuación, el fin de la medicina no es simultáneo al proceso de curación, sino que aparece una vez concluido y el paciente recupera la salud. Asimismo, Galeno invita a seguir un ejercicio continuo de escalas y ritmos que repercutan en el ánimo, siguiendo el postulado de los pitagóricos, Damón y Platón. Con sus concepciones, pues, avala el carácter paidéutico y ético de la música y, por ende, su inclusión en el programa educativo de los jóvenes, en general, y en la especialización del médico, en particular, quien es consciente de sus aplicaciones terapéuticas, como, por ejemplo, la relación entre pulsos y ritmos para el diagnóstico correcto de diversas enfermedades.

RECIBIDO: marzo 2020; ACEPTADO: marzo 2020.

${ }^{108}$ Cf. De differentia pulsuum, 8. 763.13-764.12 K. Cf. 8. 698. 5 K. Hemos preferido transcribir

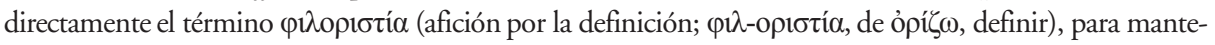
ner su significado originario, siguiendo la traducción de Sobre la diferencia de los pulsos de Luis Miguel Pino Campos (2010: 291). 


\section{REFERENCIAS BIBLIOGRÁFICAS}

Alby, J. C. (2004): «La concepción antropológica de la medicina hipocrática», Enfoques 16.1: 5-29.

Сомотті, G. (1986): La música en la cultura griega y romana. Historia de la música, 1, Madrid.

Dantas Freitas Estrela, K. A. (2018): «El papel de la música en la Política de Aristóteles», Fragmentos de cultura, Goîana 88.4: 465-471, DOI: 10.18224/frag.v28i4.6816.

DEICHGRÄBER, K., (1970): Medicus gratiotus, Wiesbaden.

De Lacy, PH. (ed.) (1978-1984): Galeni De placitis Hippocratis et Platonis, CMG, 3 vols., Berlín.

Delattre, D. (2007): Philodème de Gadara. Sur la musique (livre IV), Tomos I-II, París.

Diels, H.-Kranz, W. (eds.) (1951'): Die Fragmente der Vorsokratiker, 2 Vols., Berlín.

Eldestein, L.-KidD, I. G. (eds.) (1972): Posidonius. The fragments, Cambridge.

FUBINI, E (1988): La estética musical desde la Antigüedad hasta el siglo XX, Madrid.

GRIMAudo, S. (2008): Difendere la salute. Igiene e disciplina del soggetto nel De sanitate tuenda, Palermo.

Hagel, S. (2010): Ancient Greek Music. A New Technical History, Cambridge.

IERACI BIO, A. M. (1987): «Galeno e la concezione del medico», en Talariskos. Studia Graeca Antonio Garzya sexagenario a discipulis oblata, Nápoles, pp. 147-163.

IERACI BIO, A. M. (1991): «Sulla concezione del medico pepaideuménos in Galeno e nel tardoantico», en J. A. López Férez (ed.), Galeno: obra, pensamiento e influencia, Madrid, pp. 133-151.

JAN, K. (ed.) (1965): Musici scriptores graeci, Leipzig, pp. 420-421.

KIND, F. E. (1927): «Lykos», RE 13, cols. 2408-2417.

KüHN, G. (1821-1833): Galeni opera omnia, Leipzig (reimpr. Hildesheim, 1965).

Landels, J. G. (1999): Music in Ancient Greece and Rome, Londres-Nueva York.

Moutsopoulos, E. (1959): La musique dans l'oeuvre de Platon, París.

Nutton. V. (2004): «Erasistratus», en Brill's New Pauly Encyclopedia of the Ancient World, vol. 5, Leiden-Boston, cols. 13-15.

OtaOla, P (2011): «L'ethos des rythmes dans la théorie musicale grecque», en M. H. Delavaud-RouX, Musiques et danses dans l'Antiquité, Rennes, pp. 91-108.

Pajares Alonso, R. (2014): Historia de la música en 6 bloques. Ética y estética, vol. 6, Madrid.

Pigeaud, J. (1998): «La figure du médecin: Galien philosophe», en N. LORAUX-C. Miralles (eds.), Figures de l'intellectuel en Grèce ancienne, París, pp. 295-331.

Pino Campos, L. M. (2010): Galeno. Sobre la diferencia de los pulsos. Estudio introductorio, traducción, notas e índices, Madrid.

Rodríguez Moreno, I. (1996): «El efecto seductivo de las formulaciones mágicas en los papiros griegos», en A. Ruiz Castellanos-A. Víñez Sánchez (eds.), Diálogo y retórica, Cádiz, pp. 349-355.

Rodríguez Moreno, I. (2002): «Prácticas terapéuticas en los papiros mágicos griegos», en J. PeláEZ (ed.), El dios que hechiza y encanta. Magia y astrología en el mundo clásico y helenístico, Córdoba, pp. 79-90.

RodríGuez Moreno, I. (2009): «Música y palabra como medicina en la antigua Grecia», Calamus renascens 10: 237-255. 
Rodríguez Moreno, I. (2014): «Filosofía y medicina en la Antigüedad: dos disciplinas complementarias», en J. Ma. Maestre, J. G. Montes, R. Gallé, C. Macías, V. Pérez, S. Ramos, M. SÁnchez (eds.), Baetica Renascens, Cádiz-Málaga, pp. 265-278.

Rodríguez Moreno, I. (2018): «Texto y contexto de los términos musicales en la lírica griega arcaica», en J. A. López Férez (ed.), La lengua científica griega IV, Madrid, pp. 49-76.

Saffrey, H. D.-Segonds, A. PH. (2001): Marinus. Proclus ou Sur le bonheur, París.

ScotT, A. (1991): «Ps.-Thessalus of Tralles and Galen’s De Methodo Medendii, Sudhoffs Arch75.1: 106-110.

SouilHé, J. (1919): La notion platonicienne d'intermédiaire, París.

Stade, H. von (1989): Herophilus. The Art of Medicine in Early Alexandria, Cambridge, 1989.

SuÑol, V. (2009): «La dimensión política de las artes miméticas en Aristóteles: asimetría entre la Poética y la Políticas, Circe 13: 199-212.

Suñol, V. (2012): Más allá del arte: mímesis en Aristóteles, Buenos Aires.

Suñol, V. (2017): «La educación musical en Aristóteles: su correspondencia con una vida mejor en el mejor régimen", Boletín de estética 41: 7-35.

Suñol, V. (2018): «La función emocional de la educación musical en la Politica de Aristóteles», Práxis filosófica 47: 139-155.

TATARKIEWICZ, W. (1987): Historia de las seis ideas, Madrid.

Tatarkiewicz, W. (1991): Historia de la estética. La estética Antigua, tomo I, Madrid.

Tielman, T. (2015): «Galen on medicine as a science and as an art», History of Medicine 2.2: 132-140, DOI: $10.17720 / 2409-5834 . v 2.2 .2015 .11 \mathrm{t}$.

TOWAide, A. (2005): «Lycus of Macedon», Brill's New Pauly Encyclopedia of the Ancient World, vol. 7 , Leiden-Boston, cols. 937-940.

TOWAide, A. (2005): «Herophilus», Brill's New Pauly Encyclopedia of the Ancient World, vol. 6, LeidenBoston, cols. 274-276.

VÁZQUEZ-Hoys, A. Ma . (1994): «La magia de la palabra (aproximación a la magia, la brujería la superstición en la Antigüedad III)", ETF (his.) 7: 345-346.

Winnington-Ingram, R. P. (1968): Mode in Ancient Greek Music, Ámsterdam.

Zaragoza, J. (1992): «Magia o medicina», en J. Zaragoza-A. GonZÁlez Senmartí (eds.), Actes del Xè Simposi de la Secció Catalana de la SEEC, Tarragona, pp. 365-369. 